\title{
Contemporary Practices of Intelligence Support for Competitiveness
}

\author{
Nisha Sewdass \\ Professor, sewdan@unisa.ac.za \\ University of South Africa, Preller St, Muckleneuk, Pretoria, 0002, South Africa
}

Jonathan Calof

Professor, Telfer School of Business ${ }^{\mathrm{a}}$; Extra-ordinary Professor ${ }^{\mathrm{b}}$; Leading Research Fellow ${ }^{\mathrm{c}}$, calof@telfer.uottawa.ca

a University of Ottawa, 55 Laurier Avenue East, Ottawa, Ontario, K1N 6N5

${ }^{\mathrm{b}}$ North-West University, 11 Hoffman St, Potchefstroom, 2520, South Africa

${ }^{c}$ National Research University Higher School of Economics, 11, Myasnitskaya str., 101000, Moscow, Russian Federation

\begin{abstract}
$\mathrm{T}$ his paper focuses on the practices, assessment approaches, procedures, and applied aspects of competitive intelligence (CI). The study relies upon a survey of CI practitioners conducted in 2019 and a comparison of its results with a similar survey in 2006. It was found that companies spend the time devoted to this activity mainly on processes that go beyond collecting information, including planning, analysis, communications, and management. Most enterprises have official divisions and profile managers. The results are used to perform a variety of strategic and tactical tasks.

The main sources of information are the Internet, company employees, customers, and industry experts. Compared to 2006 , a new key resource has emerged - social networks.

Of the analytical methods, SWOT analysis and the study of competitors are most often used. Several channels of communication are used simultaneously to disseminate the received information, mainly email and presentations are used. Key performance criteria are customer satisfaction and the number of decisions made based on the information gathered.

A comparative analysis revealed that over the period separating the surveys of 2006 and 2019, the function of the CR has become more formalized. The share of companies with centralized divisions and CI managers has grown. Currently, this activity more often goes beyond the simple profiling and evaluation of competitors. Technology assessment, economic, and political analysis are more actively practiced.
\end{abstract}

\section{Keywords:}

competitive intelligence; strategic management; market insight; competitiveness; innovation; technology

Citation: Sewdass N., Calof J. (2020) Contemporary Practices of Intelligence Support for Competitiveness. Foresight and STI Governance, vol. 14, no 3, pp. 30-39. DOI: $10.17323 / 2500-2597.2020 .3 .30 .39$ 


\section{Introduction and Background}

Global markets can be regarded as "a tempestuous sea of risks and opportunities for many companies" [Stanat, 2008, p. 6]. In such an environment, competitive intelligence is held to be vital not only to help markets grow, but essentially for their survival irrespective of the size of the company [Crayon, 2019]. In addition, the rapid transformations taking place in the global economy present several challenges for global competitive intelligence. The top five challenges as identified in the State of Competitive Intelligence Report [Crayon 2019, 2020] were:

- the difficulty in obtaining accurate and reliable data sources to stay "on top" of numerous sources of information and data available,

- timeliness of the data,

- the struggle to get internal buy-in from colleagues and the whole organization,

- the distribution of CI to all stakeholders and the sharing of competitive insights,

- the struggle to turn CI findings into actionable bottom-line drivers in the organization.

Hence, it is necessary for intelligence practitioners to keep track of the evolution and changes in the CI practices worldwide [Du Toit, 2015] to ensure that the organizations succeed.

To understand how CI is adapting to these forces, CI researchers, consultants, and associations will periodically survey CI practitioners and ask about how they practice CI. The purpose of surveys of intelligence practice are usually to provide the international intelligence community with an idea of the state of intelligence practice. It also provides an indication to both the academic and practitioner community about how to assess intelligence practice as part of CI. One such study examining CI practices from around the world was conducted 14 years ago in 2006 by SCIP (Strategic and Competitive Intelligence Professionals) and the Competitive Intelligence Foundation entitled "State of the Art: Competitive Intelligence" [Fehringer et al., 2006]. The study was designed to identify how CI practitioners were working in the field at that time, differences in CI activities across industries and best practices that could be applied by companies.

In this study, we have attempted to replicate elements of the 2006 "State of the Art: Competitive Intelligence" study [Fehringer et al., 2006]. While the 2006 study does provide a basis for understanding and gauging the trends as well as the changes and consistencies in CI practices globally, the instrument that was developed by CI practitioners and academics in SCIP was revised in the present study taking into consideration developments in the CI field since 2006. Further this study examines how it has evolved over time. This study looks at multiple aspects of intelligence practice such as competitive intelligence structure and organization, intelligence focus, information sources used, analytical techniques used, communication methods, and the management of the intelligence efforts. The survey provides an updated look at how CI practitioners are practicing $\mathrm{CI}$, what $\mathrm{CI}$ is used for in organizations, and how it is evaluated. Like the 2006 study, this study also uses members of SCIP as a proxy for those that practice $\mathrm{CI}$ as the participants for the survey.

\section{CI in Perspective}

While there does not seem to be a single definition of CI that can be universally accepted [Brody, 2008; Fleisher, Bensoussan, 2007; Bulger, 2016, McGonagle, 2016; Calof et al., 2018], meta-studies on competitive intelligence have found a high degree of consistency between different authors' definitions [ $D u$ Toit, 2015].

One of the early definitions of CI seen in the literature is that of Calof and Skinner: "Competitive intelligence can be defined as actionable recommendations arising from a systematic process involving planning, gathering, analyzing and disseminating information on the external environment for opportunities or developments that can affect a company's or a country's competitive situation... CI is a systematic program for gathering and analyzing information to find new opportunities and remain competitive." [Calof, Skinner, 1998, pp. 38-39].

A little over 15 years later, Du Toit [Du Toit, 2015, p. 15] examined 338 articles about CI looking at trends in the literature between 1994 and 2014. The author provided examples of the evolution of the definition of CI and included a definition based on a meta-analysis of CI definitions as "a process or practice that produces and disseminates actionable intelligence by planning, ethically and legally collecting, processing and analyzing information from and about the internal and external or competitive environment in order to help decisionmakers in decision-making and to provide a competitive advantage to the enterprise."

This is similar to our earlier definition [Calof, Skinner, 1998]. While the definition of competitive intelligence has remained similar over the years, what has changed are the elements of how it is practiced. Bulger [Bulger, 2016, p. 57] writes "Continued globalization, vast amounts of accessible data on public platforms, and advances in technology are changing the complexity of competitive intelligence (CI) and presenting opportunities for experts with skills in this and associated fields and for organizations that utilize this expertise to create competitive advantage." Because of this change in the environment, Bulger advanced a concept called integrated intelligence which while not changing the definition, broadened the focus of intelligence and the skills required. Bulger states, "Originally, we looked at competitors. Now what we've done is actually integrated skill sets into the intelligence discipline. When I'm looking at an economic situation, I have a certain skill set that I need in order to understand economics and political situations in a 
regulatory environment. When I'm looking at competitor intelligence and market intelligence, I need a skill set that really enables me to understand marketing, understand how to segment markets, understand how to build a competitive landscape, and understand competitors" [Calof, 2016].

For the purposes of our study and given the similarity in definitions, the authors adopted the Strategic and Competitive Intelligence Professionals definition of competitive intelligence taken from the SCIP FAQ at the time of the study:

"CI is a necessary, ethical business discipline and/or skillset for decision making based on understanding the competitive environment in order to drive competitive advantage in a marketplace. Any organization that has employees gathering information or developing insights on the external environment (competitors, external environment, customers, suppliers, technology, etc.) in order to make decisions is practicing some form of CI. CI validates decision making by introducing a disciplined system not only to gather information, but also to do analysis and disseminate findings about the external environment tailored with the intent to drive competitive advantage for their organization."

As SCIP is the global association responsible for competitive intelligence accreditation it was felt that this definition was the most appropriate one to use. Embodied in this definition and the ones mentioned earlier are several dimensions:

1) A "disciplined system" with process dimension involving planning intelligence projects that will result in intelligence for decisions, the collection of information, analysis, communications, and management.

2)A "disciplined system" that has an organizational structure and personnel requirements. For example, an organizational dimension in what the SCIP definition mentions is having employees conducting these activities.

It is this broad view of CI that encompasses both process and organizational dimensions that we adopt in this paper in looking at global practices.

While we adopted this broad view of CI, there are others who view CI more as a primarily collection activity, this is a view that is seen in the marketing literature [Tanev, Bailetti, 2008]. On the ForLearn site of the European Union, foresight is defined as "a systematic, participatory, future-intelligence-gathering." 2 This definition explicitly states intelligence-gathering. The view that intelligence is about collection is so widespread that when Sharp [Sharp, 2000] wrote about "10 myths that cripple competitive intelligence" she focused a lot of attention in the article on differentiating between data ("data is material. It's numbers or facts"), information ("data in context"), and intelligence ("information that has been analyzed, and suggests actions, strategies or decisions"). Other studies have looked only at a few aspects of CI or how it could improve a specific aspect in the organization [Nasri, 2011], gathering, attitude, and use [Bisson, Tang Tong, 2018], and not the complete scope of CI.

In 2006, Fehringer et al. [Fehringer et al., 2006] conducted a study on CI practices using the broad view of $\mathrm{CI}$ as espoused for this paper. Since then many studies have been done that use this conceptualization of CI as their base. Table 1 presents those studies that have used the more holistic, broader definition of competitive intelligence.

The studies in Table 1 use the broader view of competitive intelligence. All are country or regional studies. Thus, the authors seek to add to the competitive intelligence literature by conducting a state of CI study at a global level (not regional) and look at the CI activities of all firms (not just the large firms).

There have been many studies on CI practice published after 2016 (when the study survey design was completed) but these have also been regional/country studies. For example, there are reports on CI activities of European firms [Calof et al., 2018] and Mexican firms [Ojinga, 2018]. There has also been many industry-focused studies on CI but there has not been an academic study on global CI since 2006. There however has been a host of "state of CI" reports done by consulting organizations. For example, Crayon consultants have made available to their clients and those registered for their reports annual "State of CI Competitive Intelligence" studies in 2018, 2019, and $2020{ }^{3}$ Similarly, M-Brain consultants ${ }^{4}$ have produced Global Market Intelligence Studies for over a decade, the latest was published in 2019 [M-Brain, 2019]. ${ }^{5}$ The surveys that both of these organizations (Crayon and $\mathrm{M}$-Brain) conducted are similar to the one used in the studies listed above and ask questions about CI practices, structure, focus, communications, management, and so on - the comprehensive view of competitive intelligence mentioned earlier.

Similar to past CI studies, no hypotheses are advanced. The objectives are to help organizations understand how CI is being practiced. While the objective is not to compare the results from the study [Fehringer et al., 2006], since 2006 there have been several global trends that are driving the need for competitive intelligence that could result in changes to CI practice [Bulger, 2016, p. 58; Stanat, 2008; M-Brain, 2015]. These include:

- The globalization of markets and the variation of the needs of each market.

\footnotetext{
Available at: www.scip.org, accessed 19.03.2020.

Available at: http://www.foresight-platform.eu/community/forlearn/what-is-foresight/, accessed 19.03.2020.

${ }^{3}$ Available at: www.crayon.com, accessed 19.03.2020.

${ }^{4}$ Formerly Global Intelligence Alliance

Available at: m-brain.com, accessed 19.03.2020.
} 
Table 1. Example of CI practice Studies after Fehringer, 2006-2016

\begin{tabular}{|c|c|c|c|c|c|}
\hline Study & Geographic focus & Industry focus & Sample & Firms & CI Definition \\
\hline [Badr et al., 2006] & Europe & $\begin{array}{l}\text { Pharmaceutical } \\
\text { industry }\end{array}$ & 79 & All sizes & Technological foresight \\
\hline [Dishman, Calof, 2008] & Canada & Technology & 1025 & All sizes & $\begin{array}{l}\text { Competitive technical intelligence, } \\
\text { Competitive analysis. }\end{array}$ \\
\hline [Du Toit, Sewdass, 2014] & Morocco & All & 25 & All sizes & $\begin{array}{l}\text { Economic intelligence, Social } \\
\text { intelligence, Competitive technical } \\
\text { intelligence }\end{array}$ \\
\hline [Sewdass, Du Toit, (2014] & South Africa & All & 24 & All sizes & $\begin{array}{l}\text { Competitive intelligence, } \\
\text { Strategic intelligence }\end{array}$ \\
\hline [Sewdass, Du Toit, 2015] & $\begin{array}{l}\text { Brazil and South } \\
\text { Africa }\end{array}$ & All & 37 & All sizes & $\begin{array}{l}\text { Competitive intelligence, } \\
\text { Strategic intelligence, Economic } \\
\text { intelligence }\end{array}$ \\
\hline [Barnea, 2016] & Israel & All & 39 & Large & $\begin{array}{l}\text { Competitive intelligence, } \\
\text { Military intelligence }\end{array}$ \\
\hline
\end{tabular}

- The abundance of data - easily accessible and inexpensive with advanced technological developments.

- Shorter innovation cycle times - improving time to market, costs, and increasing competitiveness.

- Integrated approaches designed to comprehensively understand not only competitors, but also customers and the macro-environment and collaboration with other functional areas used to gain a comprehensive picture of a market.

It has been noted that in the global competitive environment, the relationships among people, markets, and business processes are becoming increasingly interlinked. Furthermore, globalization does not mean that all organizations standardize their local practices but instead they adapt global processes and practices to their local traditional environments [Stanat, 2008]. Hence these competitive companies practice $\mathrm{CI}$ within the bounds of their markets and local governmental policies as well as within global markets and standards.

\section{Methodology \\ Survey instrument design}

The development of a CI research instrument started with the one developed for the "State of the Art: Competitive Intelligence" study [Fehringer et al., 2006] given that this instrument is recognized as a comprehensive one reflecting the breadth of the intelligence definition adopted for this paper and consistent with the professional association representing the field.

In the paper [Fehringer et al., 2006], the authors presented the survey and the ensuing study as:

"the first of its kind...comprehensive view of the current competitive intelligence field... To create the survey, we reviewed the questions asked in previous competitive intelligence surveys conducted by SCIP and by competitive intelligence consultants and vendors. We also solicited suggestions from the SCIP Meritorious and
Fellows award recipients, and from individuals who are involved in the Foundation's Advisory councils." (p. 5-6)

Given the comprehensiveness of this survey and the methodology for its development, it formed the basis for our survey in this study and we followed a similar methodology to their study both in terms of survey design and execution.

Given the developments in the CI field mentioned in the CI in Perspective section (for example the broadening of the skills and focus under the integrated intelligence concept) and the global changes mentioned earlier, the authors of [Fehringer et al., 2006] recognized that the questionnaire would have to have to be revised. The researchers reviewed the questions used in the studies noted in Table 1 (and others). The researchers also reviewed the competitive intelligence literature post-2006 for developments in the field that should be included in the survey. For example, the researchers looked over issues of the Journal of Intelligence Studies in Business and noted in several articles a lot of mentions of social media and analytics for competitive intelligence. These were not included in the 2006 survey but given their prominence in the current literature, we brought it into the new survey. Hence, a question pertaining to the use of social media sources for competitive intelligence and a question about which analytical techniques or models were used in organizations were added to the revised questionnaire. The questionnaire was also revised based upon discussions with industry practitioners, academics, and association personnel. One of the new questions that emerged from this group was on trade show intelligence. A topic that has grown in the CI field since 2006.

The revised questionnaire was then sent to five leading CI academics and practitioners for comment, additions, and validation. The revised survey was then pre-tested on SCIP members and revised again based on their feedback. 


\section{Sample framework and responses}

The targeted population for this study were members of SCIP. This was a similar sample to that of [Fehringer et al., 2006]. These are practicing CI professionals from various industries and countries. Similar to the 2006 study, SCIP agreed to administer the survey to their members. They promoted the survey in multiple newsletters, on their website, in emails to their chapter chairs, and at SCIP events including conferences and chapter meetings. In addition, SCIP chapter chairs were asked to send an email to those on their chapter contact list reminding them about the survey and asking them to complete it.

This resulted in 436 questionnaires being returned. Of these, 264 provided full details of their competitive in telligence practices while the rest provided overview information such as type of industry, size, geographic location, and a few details of their intelligence operations but not enough details for purposes of this article. Thus, it is these 264 respondents that we report upon. The actual response rate is difficult to calculate for two reasons:

1) Overall SCIP membership numbers are not provided by the association as this was felt to be confidential information, however they said that the number of respondents would represent more than $30 \%$ of membership,

2) While inclusion of the survey link in SCIP publications targeted only SCIP members, non-SCIP members do attend SCIP conferences and chapter events. In terms of the 264 surveys used, $63 \%$ were from SCIP members.

As mentioned in the CI in Perspective section, this study seeks to have a global focus and study firms of all sizes. This addresses a weakness identified in the literature. Of the respondents, $41 \%$ were from Europe, $43 \%$ from the United States, $4 \%$ from South America, and $12 \%$ from other regions. In terms of firm size, our objective was to have representation from more than just large firms and this was accomplished. Sixteen percent of respondents came from firms with under $100 \mathrm{em}-$ ployees, 22\% from firms with less than 500 employees, 9\% from firms with between 500 and 999 employees, and the rest from larger firms. These numbers mirror SCIP membership, but more importantly for the study, they provide a base of firms that are global and of diverse sizes.

\section{Results}

This section reports on the results of the survey. Given the similar methodology as was used by [Fehringer et al., 2006] both in terms of the method for survey development, the use of SCIP members, and the help of SCIP in administering the questionnaire, comparisons are done for several of the questions in the findings section. While not statistically validated, it does provide an indication as to how $\mathrm{CI}$ practice has changed since 2006.
Table 2. The Intelligence Process: the Percentage of Project Time Focused on CI Activities

\begin{tabular}{|l|l|}
\hline \multicolumn{1}{|c|}{ Type of activity } & $\begin{array}{c}\text { Percentage } \\
\text { of time spent }\end{array}$ \\
\hline Planning the intelligence project & $13 \%$ \\
\hline $\begin{array}{l}\text { Collecting the information required for the CI } \\
\text { project(s) }\end{array}$ & $29 \%$ \\
\hline $\begin{array}{l}\text { Analysis (piecing together collected data and } \\
\text { analyzing) }\end{array}$ & $23 \%$ \\
\hline $\begin{array}{l}\text { Communicating the intelligence (formatting } \\
\text { intelligence deliverables, writing the reports, etc.) }\end{array}$ & $18 \%$ \\
\hline $\begin{array}{l}\text { Managing the project including meeting with the } \\
\text { clients }\end{array}$ & $10 \%$ \\
\hline Evaluating the intelligence project & $7 \%$ \\
\hline Source: authors. & \\
\hline
\end{tabular}

\section{Creating intelligence vs collecting intelligence}

As mentioned in the CI in Perspective and Methodology sections above, there are those who see intelligence as collection-based (you collect intelligence) and others who see it as a more comprehensive process (you create intelligence). Like past studies, as discussed above under CI in Perspective and in Table 1, we addressed the different views by asking respondents what percentage of their time was spent on collection activities versus other activities in their intelligence projects.

Is CI more than just collection? In our study, no survey response listed collection activities as taking $100 \%$ of the time spent on CI. The highest amount of time that any of the 264 respondents said they spent in collection activities as part of their CI process was between $61 \%$ and $80 \%$ and only $2 \%$ of the respondents were within this range. A total of $10 \%$ replied that between $41 \%$ and $60 \%$ of their CI time was spent on collection. On average, respondents indicated that $29 \%$ of their intelligence time focused on collection (Table 2) with $23 \%$ of intelligence time devoted to analyzing the information. The responses in Table 2 are consistent with the broader, more holistic view of intelligence that was adopted for this study.

The study [Fehringer et al., 2006] did not ask respondents how much time was spent on each activity but

\section{Table 3. Structure of the Intelligence Function}

\begin{tabular}{|l|l|}
\hline \multicolumn{1}{|c|}{ Type of structure } & Percentage \\
\hline $\begin{array}{l}\text { Centralized: one CI function serves all or most of } \\
\text { the organization }\end{array}$ & $42 \%$ \\
\hline $\begin{array}{l}\text { Decentralized: each department or functional line } \\
\text { of business does its own competitive intelligence }\end{array}$ & $10 \%$ \\
\hline Hub and spoke organization but centrally driven & $1 \%$ \\
\hline $\begin{array}{l}\text { Informal: no structured CI function at any level, } \\
\text { CI tasks occur only as needed and may or may } \\
\text { not be labelled as "Cl" }\end{array}$ & $13 \%$ \\
\hline $\begin{array}{l}\text { Mixed: some activities are centralized, others are } \\
\text { done independently by Individual departments or } \\
\text { functional lines of business }\end{array}$ & $34 \%$ \\
\hline Source: authors. & \\
\hline
\end{tabular}


Table 4. Name of Department Responsible for Competitive Intelligence

\begin{tabular}{|l|l|}
\hline \multicolumn{1}{|c|}{ Name of unit } & \multicolumn{1}{c|}{$\begin{array}{c}\text { Percentage } \\
\text { of respondents }\end{array}$} \\
\hline Competitive intelligence & $27 \%$ \\
\hline Marketing intelligence & $15 \%$ \\
\hline Marketing/market research & $12 \%$ \\
\hline Strategic planning & $11 \%$ \\
\hline Multiple units & $10 \%$ \\
\hline Business intelligence & $7 \%$ \\
\hline Market insight & $5 \%$ \\
\hline Competitor insight & $3 \%$ \\
\hline Other names & $10 \%$ \\
\hline Source: authors. & \\
\hline
\end{tabular}

asked them to rank the activities based on how much time was spent on them. The change in this study's survey arose as the experts/reviewers stated that putting in the percentage of time was more consistent with the recent literature. However, consistent with our results, in the study [Fehringer et al., 2006], collection activities ranked first and analysis second in terms of the amount of time taken. All other elements of Table 2 had more than $10 \%$ of the respondents ranking them as taking significant $\mathrm{CI}$ project time.

\section{Intelligence structure and processes}

Respondents were provided with a list of five different types of structures for intelligence (including having no formal structure) and eight different titles for the unit (if it existed). Tables 3 and 4 present these results. The two most dominant CI structures were centralized units (one at the organization - $42 \%$ ) followed by a mixed approach where there was a centralized unit and additional intelligence activities conducted throughout the organization (34\%). A total of $13 \%$ replied that they did not have a formal unit. The number of those without a formal unit declined compared to the results in [Fehringer et al., 2006] in which $20 \%$ did not have a unit, while a total of $34 \%$ had a centralized unit. This increase in formal CI was also noted in [Calof et al., 2018] who reported in their study on European CI activities how CI had become more formalized over the past 10 years.

\section{Table 5. Formality of Competitive Intelligence Efforts}

\begin{tabular}{|l|l|l|}
\hline \multirow{2}{*}{ Formality level } & \multicolumn{2}{l|}{ \% Responding ) } \\
\cline { 2 - 3 } & Yes & No \\
\hline Formal CI strategy & 44.7 & 55.3 \\
\hline Formal CI procedures & 42.3 & 57.7 \\
\hline CI ethical guidelines & 56.5 & 43.5 \\
\hline Manager with CI responsibilities & 71.2 & 28.8 \\
\hline $\begin{array}{l}\text { Note: the total sum of responses in the columns exceeds 100\% due to } \\
\text { respondents being permitted to choose several response options. } \\
\text { Source: authors. }\end{array}$ \\
\hline
\end{tabular}

Regarding the name of the department responsible for $\mathrm{CI}-\mathrm{CI}$ and market intelligence were number 1 and 2 , respectively, but of note was the fact that $10 \%$ of respondents indicated multiple departments responsible for CI.

When asked how many full-time employees they had supporting CI, companies' most frequent response was $2-4$ employees (37\%), 33\% having 1 or fewer, $167 \%$ had 5-9, and $15 \%$ had greater than 10 .

\section{Competitive intelligence procedures}

The survey had several questions regarding the extent to which CI was formalized within the respondents' organizations: the formalization of a CI strategy, CI procedures, specific CI ethical guidelines, and a manager with CI responsibilities. Results are reported in Table 5. In comparing the results with the study [Fehringer et al., 2006], as mentioned earlier it appears that CI has become more entrenched and formalized. For example, $71.2 \%$ of this study's respondents had a manager with CI responsibilities compared $50.2 \%$ of the 2006 study.

The study also examined the extent of employee awareness of and involvement in CI. Only $1 \%$ reported that none of the organization employees knew that CI existed with $5 \%$ reporting that no employee participated in CI activities (Table 6). In comparing the results with the study [Fehringer et al., 2006], 3.3\% indicated that no employee participated in CI. These results are consistent with the broader and more holistic definitions of competitive intelligence that have more than just competitive intelligence unit employees involved in competitive intelligence activities.

\section{Intelligence focus}

Regarding the focus of intelligence, respondents were asked about the business decisions supported by CI and the type of intelligence products developed (for example market entry reports, benchmarking - Tables 7 and 8). Innovation-related intelligence topics were frequently mentioned including $\mathrm{R} \& \mathrm{D}$ decisions and new product development. These results are very similar to [Fehringer et al., 2006] with the exception of technology-related intelligence which was rated higher in this study. In [Fehringer et al., 2006] technological intelligence was ranked lower and had $24 \%$ responding that

\section{Table 6. Company-Wide Knowledge and} Involvement in CI

\begin{tabular}{|l|l|l|}
\hline \multirow{2}{*}{} & \multicolumn{2}{|c|}{ Organizations employees that } \\
\cline { 2 - 3 } & \multicolumn{1}{|c|}{ know CI exists } & $\begin{array}{c}\text { participate in CI } \\
\text { activities }\end{array}$ \\
\hline None & $1 \%$ & $5 \%$ \\
\hline Few & $18 \%$ & $37 \%$ \\
\hline Some & $35 \%$ & $42 \%$ \\
\hline Most & $26 \%$ & $11 \%$ \\
\hline All & $10 \%$ & $5 \%$ \\
\hline Source: authors. & \multicolumn{2}{|l}{} \\
\hline
\end{tabular}


Table 7. Frequency of Issuing Competitive Intelligence Products

\begin{tabular}{|l|l|l|}
\hline \multicolumn{1}{|c|}{ Format } & Average & \multicolumn{1}{c|}{$\begin{array}{c}\text { Percent } \\
\text { responding } \\
\text { frequently }\end{array}$} \\
\hline $\begin{array}{l}\text { Market industry/report/ } \\
\text { analysis }\end{array}$ & 2.4 & $54 \%$ \\
\hline Benchmarking & 2.2 & $39 \%$ \\
\hline Company profiles & 2.4 & $51 \%$ \\
\hline Early warning alert & 1.8 & $32 \%$ \\
\hline Technology assessments & 1.8 & $31 \%$ \\
\hline Economic analysis & 1.7 & $25 \%$ \\
\hline Customer profiles & 1.8 & $30 \%$ \\
\hline Executive profiles & 1.6 & $18 \%$ \\
\hline Political analysis & 1.4 & $15 \%$ \\
\hline Supplier profiles & 1.1 & $10 \%$ \\
\hline $\begin{array}{l}\text { Note: the responses were measured on a four-point scale (0 never to 3 } \\
\text { frequently); the total sum of responses exceeds 100\% due to respondents } \\
\text { being able to choose several response options. } \\
\text { Source: authors. }\end{array}$ \\
\hline
\end{tabular}

it was frequently a focus in their CI program versus $31 \%$ in the present study. Further, economic analysis was frequently produced in $25 \%$ of the respondent's organizations and political analysis in $15 \%$ while in the study [Fehringer et al., 2006] the combined economic and political analysis selection was noted as frequently produced by $17 \%$ of the respondents. Market industry was mentioned as a frequent product by $54 \%$ of the respondents in this study versus $32 \%$ in the [Fehringer et al., 2006]. Therefore, it would appear that consistent with the integrated intelligence view, respondents' in telligence focus is broader now than it was in 2006.

A final aspect of focus examined in the study was the temporal orientation of the intelligence process, that is, how forward-looking the intelligence was. Respondents indicated that $50 \%$ of intelligence proj-

\section{Table 8. Business Decisions Supported} by $\mathrm{CI}$ in the Organization

\begin{tabular}{|l|l|l|}
\hline \multicolumn{1}{|c|}{ Decision type } & \multicolumn{1}{|c|}{ Average } & \multicolumn{1}{|c|}{$\begin{array}{c}\text { \% responding } \\
\text { frequently }\end{array}$} \\
\hline Sales or business development & 2.3 & 49 \\
\hline Corporate or business strategy & 2.3 & 47 \\
\hline Market entry decisions & 2.1 & 39 \\
\hline Product development & 2.1 & 39 \\
\hline $\begin{array}{l}\text { Research or technology } \\
\text { development }\end{array}$ & 2.0 & 31 \\
\hline $\begin{array}{l}\text { Mergers and acquisitions, } \\
\text { due diligence, joint-venture } \\
\text { assessment }\end{array}$ & 1.8 & 27 \\
\hline Regulatory or legal & 1.6 & 17 \\
\hline $\begin{array}{l}\text { Reputation management/ } \\
\text { communications/Public } \\
\text { relations }\end{array}$ & 1.5 & 19 \\
\hline $\begin{array}{l}\text { Note: the responses were measured on a four-point scale (0 never } \\
\text { to 3 frequently); the total sum of responses exceeds 100\%, due to } \\
\text { respondents being able to choose several response options. } \\
\text { Source: authors. }\end{array}$ \\
\hline
\end{tabular}

Table 9. Temporal Orientation of CI Projects (how forward-looking intelligence projects are)

\begin{tabular}{|l|l|}
\hline $\begin{array}{c}\text { Forward looking } \\
\text { by how many } \\
\text { years }\end{array}$ & \multicolumn{1}{|c|}{$\begin{array}{c}\text { Percent of time with this temporal } \\
\text { orientation }\end{array}$} \\
\hline$<$ One year & $50 \%$ \\
\hline One to five years & $37 \%$ \\
\hline Six to ten years & $9 \%$ \\
\hline$>10$ years & $4 \%$ \\
\hline Source: authors.
\end{tabular}

ects looked forward less than one year, 37\% looked forward 1-5 years, and 13\% looked forward more than 5 years (Table 9). This question was not part of the study [Fehringer et al., 2006] and reflects the growing importance of technology-related topics that have a longer temporal orientation.

\section{Information sources used}

Respondents indicated that the information collected for their intelligence efforts came from a broad range of sources. With the growth of the internet in terms of providing a broad range of both primary and secondary information, it was not surprising that this was the top source of information (3.3 in terms of its importance on a scale of zero to four and $54 \%$ in terms of it being noted as a very important source - Table 10). Other secondary sources such as publications and company databases were next in terms of importance in respondents' collection efforts (2.9 and 2.8). However, primary sources such as customers, employees, and industry experts were similar in importance to these other secondary sources (2.8 and 2.7). Given the responses in Table 6 with 95\% of respondents stating that their employees are involved in their organizations' competitive intelligence efforts, it is not surprising that employees were amongst the more important sources of information noted in our study. The survey [Fehringer et al., 2006] did not list social media but had a similar ranking as this study. In [Fehringer et al., 2006], however, company employees were much more highly rated as a source.

\section{Analytical methods or models used}

Eighty-three percent responded that they used some kind of analytical model to develop intelligence with most using more than one model (on average, 5.4 techniques were used). Most frequently used were SWOT (Strength, weakness, opportunities, and threats analysis) and competitor analysis (83\%), followed by benchmarking (69\%), competitive positioning analysis (49\%), and industry analysis (45\%) - as illustrated in Table 11. The study [Fehringer et al., 2006] also asked about the different techniques and the top two used in this study were also SWOT and competitor analysis. 


\section{Communication of intelligence findings}

Email and presentations/staff briefings were the most frequently used methods for communicating intelligence findings (Table 12) with all respondents using multiple methods for communicating their findings. In comparing these results to the study [Fehringer et al., 2006], it is not surprising that many of the nonelectronic methods for communicating were more frequently used. For example, in the study [Fehringer et al., 2006], printed alerts or reports were the second most frequently mentioned communication vehicles (45\% frequently used versus $39 \%$ in this study) and, personal delivery was listed as frequently used by $37 \%$ of the respondents (versus $22 \%$ for this study). In comparison, the central database was listed as frequently used by $40 \%$ of the respondents in this study versus $32 \%$ in the study [Fehringer et al., 2006] with email being virtually the same.

\section{CI management/assessing CI effectiveness}

The most frequently used method for assessing CI effectiveness was customer (the end user of the intelligence products) satisfaction followed by decisions made/supported (Table 13). Only 10\% reported that they had no effectiveness measures. This result is in contrast with the study [Fehringer et al., 2006] in which $30 \%$ of the respondents indicated that they did not have a CI effectiveness measure and 35\% said they did not have a CI value measure. However, similar to the study [Fehringer et al., 2006], customer satisfaction

\section{Table 10. Sources of Information for CI}

\begin{tabular}{|l|l|l|}
\hline \multicolumn{1}{|c|}{ Information source } & Score (0-4) & $\begin{array}{l}\text { Percent responding } \\
\text { very important }\end{array}$ \\
\hline 1. Internet websites (free) & 3.3 & $52 \%$ \\
\hline $\begin{array}{l}\text { 2. Publications (print/ } \\
\text { online) }\end{array}$ & 3.0 & $39 \%$ \\
\hline 3. Commercial databases & 2.9 & $38 \%$ \\
\hline 4. Customers & 2.9 & $30 \%$ \\
\hline 5. Company employees & 2.9 & $29 \%$ \\
\hline 6. Industry experts & 2.8 & $28 \%$ \\
\hline 7. Internal databases & 2.7 & $27 \%$ \\
\hline 8. Trade show/conference & 2.4 & $18 \%$ \\
\hline 9. Social media & 2.3 & $14 \%$ \\
\hline $\begin{array}{l}\text { - Blogs/wiki used for } \\
\text { CI }\end{array}$ & 2.2 & $18 \%$ \\
\hline - LinkedIn used for CI & 2.7 & $33 \%$ \\
\hline - Twitter used for CI & 2.0 & $19 \%$ \\
\hline - Facebook used for CI & 1.7 & $15 \%$ \\
\hline 10. Suppliers & 2.0 & $10 \%$ \\
\hline $\begin{array}{l}\text { 11. Government } \\
\text { employees }\end{array}$ & 1.5 & $8 \%$ \\
\hline $\begin{array}{l}\text { 12. Association } \\
\text { employees }\end{array}$ & 1.5 & $4 \%$ \\
\hline $\begin{array}{l}\text { Note: the responses were measured on a five-point scale (0 not important } \\
\text { at all to 4 very important); the total sum of responses exceeds 100\% due to } \\
\text { respondents being able to choose several response options. } \\
\text { Source: authors. }\end{array}$ & \\
\hline
\end{tabular}

Table 11. Respondents' Use of Analytical Methods and Models

\begin{tabular}{|l|r|}
\hline \multicolumn{1}{|c|}{ Technique used } & $\begin{array}{c}\text { Percent using the } \\
\text { technique }\end{array}$ \\
\hline 1 SWOT Analysis & $83 \%$ \\
\hline 2 Competitor Analysis & $83 \%$ \\
\hline 3 Benchmarking (Best practices) & $69 \%$ \\
\hline 4 Competitive Positioning Analysis & $49 \%$ \\
\hline 5 Industry Analysis & $45 \%$ \\
\hline 6 Financial Analysis and Valuation & $41 \%$ \\
\hline 7 Customer Segmentation Analysis & $40 \%$ \\
\hline 8 Scenario Analysis & $40 \%$ \\
\hline 9 Patent Analysis & $23 \%$ \\
\hline 10 Technology Forecasting & $22 \%$ \\
\hline 11 Indications and Warning Analysis & $21 \%$ \\
\hline $\begin{array}{l}\text { Note: the total sum of responses exceeds 100\% due to respondents being } \\
\text { able to choose several response options. } \\
\text { Source: authors. }\end{array}$ \\
\hline
\end{tabular}

and decisions made/supported were the top two CI effectiveness measures. Similar to the findings in the CI structure section, $35 \%$ of the 2006 sample not having effectiveness measures versus $10 \%$ in this study does support the idea that CI has become more formalized at practicing organizations.

\section{Conclusion}

The objective of this paper was to examine how intelligence is practiced and, in a sense, provide the Foresight and STI Governance community with insights in terms of:

1) How competitive intelligence practitioners define and operationalize the measurement of competitive intelligence

2)Report on how competitive intelligence activities are being practiced.

\section{Table 12. Communicating CI Results}

\begin{tabular}{|c|c|c|}
\hline Communication channel & $\begin{array}{l}\text { Average } \\
\text { response }\end{array}$ & $\begin{array}{l}\text { Percent } \\
\text { responding } \\
\text { frequently }\end{array}$ \\
\hline E- mails & 2.6 & $68 \%$ \\
\hline Presentations/staff briefings & 2.3 & $48 \%$ \\
\hline Central database & 1.9 & $40 \%$ \\
\hline Printed alerts or reports & 1.8 & $39 \%$ \\
\hline Company intranet & 1.8 & $38 \%$ \\
\hline Newsletters & 1.7 & $37 \%$ \\
\hline Warning alerts & 1.6 & $22 \%$ \\
\hline Teleconference & 1.6 & $21 \%$ \\
\hline Personal delivery & 1.5 & $22 \%$ \\
\hline \multicolumn{3}{|c|}{$\begin{array}{l}\text { Note: the responses were measured by a four-point scale ( } 0 \text { never to } 3 \\
\text { frequently); the total sum of responses exceeds } 100 \% \text { due to respondent } \\
\text { being able to choose several response options. } \\
\text { Source: authors. }\end{array}$} \\
\hline
\end{tabular}


Table 13. Assessing CI Effectiveness

\begin{tabular}{|l|l|}
\hline Metric for assessing CI effectiveness & \multicolumn{1}{|c|}{$\begin{array}{c}\text { Percent of } \\
\text { respondents using } \\
\text { the metric }\end{array}$} \\
\hline Customer satisfaction & $34 \%$ \\
\hline Decisions made/supported & $30 \%$ \\
\hline CI productivity/output & $24 \%$ \\
\hline Strategies enhanced & $22 \%$ \\
\hline New or increased revenue & $18 \%$ \\
\hline New products or services developed & $14 \%$ \\
\hline Cost savings or avoidance & $13 \%$ \\
\hline We have no effectiveness measure & $10 \%$ \\
\hline Time savings & $10 \%$ \\
\hline Profit savings & $10 \%$ \\
\hline Financial goals met & $10 \%$ \\
\hline Return on investment & $8 \%$ \\
\hline $\begin{array}{l}\text { Note: the total sum of responses exceeds } 100 \% \\
\text { ble to choose several response options. } \\
\text { Source: authors.. }\end{array}$ & \\
\hline
\end{tabular}

The study reported on the results from 264 respondents. The respondent companies were diverse in terms of size and geography. Using the Strategic and Competitive Intelligence Professionals (SCIP) membership as a basis for the study ensured that the survey would be sent to those associated with the practice of competitive intelligence. First, in terms of how the practitioners themselves define competitive intelligence, the study results supported a broader definition of competitive intelligence, beyond just collecting information. A total of $71 \%$ of competitive intelligence project time was taken up by non-collection activities including planning, analysis, communication, and management activities.

Organizationally, the study results also support the notion of a more formalized approach to competitive intelligence with $71 \%$ of the respondents having a manager with identified responsibility for competitive in telligence activities and $87 \%$ of all responding organizations having some form of formal CI structure. This kind of formal, company-wide effort was also reflected in the fact that in only $5 \%$ of the responding companies were employees of the company not involved with intelligence activities. In terms of intelligence focus, intelligence was used by the responding companies for many different types of strategic and tactical business decisions.

Regarding the collection side of intelligence, while the internet was clearly the number one source of information for company's intelligence efforts, a cluster of the second most important sources included primary sources such as company employees, customers, and industry experts. Respondents used on average 5.4 analytical techniques with SWOT and competitor analysis being the most frequently used.

Email and presentations were the most used approaches used for communicating intelligence with most respondents using multiple communications approaches. Finally, assessing intelligence effectiveness, an area of increasing importance in CI was noted as important in this study with only $10 \%$ of respondents to this question not having any effectiveness measures. The most frequently used measures were customer satisfaction and decisions made due to the intelligence.

Throughout the paper, the authors have compared various results of this study with a similar study conducted in 2006 [Fehringer et al., 2006]. Readers are cautioned that the differences in some of the questions, their measurement, and the fact that no statistical measures were used in comparison limits the statistical validity of the conclusions. However, it does appear, based on a cursory examination of the two studies, that $\mathrm{CI}$ is more formal today than it was in 2006 with a higher percentage of respondents having centralized units and CI managers. Further, consistent with the shift in intelligence towards a broader mandate (integrated intelligence) the survey noted that compared to [Fehringer et al., 2006], CI deliverables were more likely to involve more than just profiling and competitor assessments. For example, we noted increases in technology assessments, economic, and political analysis. This supports the notion of integrated intelligence [Bulger, 2016].

While this study has been successful in examining how competitive intelligence is practiced and identifying some changes in field since 2006 based on a cursory examination, a limitation of this study is that only members of SCIP (CI association) and those attending SCIP functions were used as a proxy for those that practice CI as the participants of the survey. In addition, only 264 responses received were complete and usable. It would be useful in future to conduct such a study with more CI practitioners and to include those that are not affiliated with SCIP. Future studies could also look at using analytics and statistical methods to test relationships and to measure CI practices at organizations. Finally, it would be useful to move towards causal models in studying competitive intelligence and cluster approaches as well that could help the field identify attributes associated with successful practice.

The study was prepared within the framework of the Basic Research Program at the National Research University HSE and supported within the framework of a subsidy by the Russian Academic Excellence Project "5-100"”

\section{References}

Badr A., Madden E., Wright S. (2006) The contribution of CI to the strategic decision-making process: Empirical study of the

European pharmaceutical industry. Journal of Competitive Intelligence and Management, vol. 3, no 4, pp. 15-35.

Barnea A. (2016) Study on Competitive Intelligence in Israel. Journal of Intelligence Studies in Business, vol. 6, no 2, pp. 5-16. 
Bisson C., Tang Tong M.M. (2018) Investigating the competitive intelligence practices of Peruvian fresh grapes exporters. Journal of Intelligence Studies in Business, vol. 8, no 2, pp. 43-61.

Brody R. (2008) Issues in defining competitive intelligence: An exploration. Journal of Competitive Intelligence and Management, vol. 4, no 3, pp. 3-16.

Bulger N.J. (2016) The Evolving Role of Intelligence: Migrating from Traditional Competitive Intelligence to Integrated Intelligence. The International Journal of Intelligence, Security, and Public Affairs, vol. 18, no 1, pp. 57-84. DOI: $10.1080 / 23800992.2016 .1150691$.

Calof J., Skinner B. (1998) Competitive intelligence for managers. Optimum, vol. 28, no 2, pp. 38-43.

Calof J.L. (2016) Government sponsored competitive intelligence for regional and sectoral economic development: Canadian experiences. Journal of Intelligence Studies in Business, vol. 6, no 1, pp. 48-58.

Calof J. (2017a) Canadian competitive intelligence practices - a study of practicing strategic and competitive intelligence professionals' Canadian members. Foresight, vol. 19, no 6, pp. 577-589. Available at: https://doi.org/10.1108/FS-07-20170024, accessed 26.05.2020.

Calof J. (2017b) Reflections on the Canadian Government in competitive intelligence - programs and impacts. Foresight, vol. 19, no 1, pp. 31-47. Available at: https://doi.org/10.1108/FS-08-2016-0038, accessed 26.05.2020.

Calof J.L., Arcos R., Sewdass N. (2018) Competitive intelligence practices of European firms. Technology Analysis and Strategic Management, vol. 30, no 6, pp. 658-671. DOI: 10.1080/09537325.2017.1337890.

Crayon (2019) State of Competitive Intelligence 2019. Available at: https://www.crayon.co/state-of-competitive-intelligence, accessed 02.05.2019.

Crayon (2020) State of Competitive Intelligence 2020. Available at: https://www.crayon.co/state-of-competitive-intelligence, accessed 02.02.2020.

Dishman P.L., Calof J.L. (2008) Competitive intelligence: A multiphasic precedent to marketing strategy. European Journal of Marketing, vol. 42, no 7/8, pp. 766-785.

Du Toit A. (2015) Competitive intelligence research: An investigation of trends in the literature. Journal of Intelligence Studies in Business, vol. 5, no 2, pp. 14-21.

Du Toit A.S.A., Sewdass N. (2014) Competitive intelligence in Morocco. African Journal of Library, Archives and Information Science, vol. 24, no 1, pp. 3-13.

Fehringer D., Hohhof B., Johnson T. (eds.) (2006) State of the Art Competitive Intelligence (Competitive Intelligence Foundation Research Report), Alexandria, VA: Society of Competitive Intelligence Professionals.

Fleisher C.S., Bensoussan B.E. (2007) Business and Competitive Analysis. Upper Saddle River, NJ: FT Press.

M-Brain (2015) Global Market Intelligence Survey 2015. Available at: https://www.m-brain.com/blog-posts/2015-marketintelligence-survey-report/, accessed 12.02.2020.

M-Brain (2019) Global Market Intelligence Survey 2019. Available at: https://www.m-brain.com/white-papers/globalintelligence-survey-2019/ accessed 17.03.2020.

McGonagle J.J. (2016) Guide to the study of intelligence. Journal of U.S. Intelligence Studies, vol. 22, no 2, pp. 55-59.

Nasri W. (2011) Competitive Intelligence in Tunisian Companies. Journal of Enterprise Information Management, vol. 24, no 1, pp. 53-67.

Ojinaga E.R.P. (2018) Exploratory study of competitive intelligence in Mexico. Journal of Intelligence Studies in Business, vol. 8, no 3, pp. 22-31.

Sewdass N., Du Toit A.S.A. (2014) Current state of competitive intelligence in South Africa. International Journal of Information Management, vol. 34, no 2, pp. 185-190.

Sewdass N., Du Toit A.S.A. (2015) Competitive Intelligence in emerging economies: A comparative study between Brazil and South Africa. TD The Journal of Transdisciplinary Research in Southern Africa, vol. 11, no 1, pp. 113-132.

Sharp S. (2000) Truth or Consequences: 10 Myths that Cripple Competitive Intelligence. Competitive Intelligence Magazine, vol. 3, no 1, pp. 1-6.

Stanat R. (2008) Global competitive intelligence blueprint. Competitive Intelligence Magazine, vol. 11, no 3, pp. 6-11.

Tanev S., Bailetti T. (2008) Competitive intelligence information and innovation in small Canadian firms. European Journal of Marketing, vol. 42, no 7/8, pp. 786-803. Available at: https://doi.org/10.1108/03090560810877150, accessed 16.04.2020. 